\title{
DEMOCRACIA E AS AGENDAS REFORMISTAS NA AMÉRICA LATINA
}

\author{
DEMOCRACIA Y LAS AGENDAS REFORMISTAS EN AMÉRICA LATINA
}

DEMOCRACY AND THE REFORMIST AGENDAS IN LATIN AMERICA

\author{
Bárbara Carvalho NEVES ${ }^{1}$ \\ André Leite ARAUJO²
}

RESUMO: Este artigo discute os programas reformistas na Bolívia, no Brasil, no Equador e na Venezuela, durante o século XXI, e as suas limitações conjunturais. Nesse contexto, questões econômicas, jurídicas, políticas e sociais de ordem doméstica e internacional são analisadas como fatores de contradição que explicam a manutenção do sistema capitalista e a dificuldade de realização plena do regime democrático na região. Considerando as particularidades de cada Estado analisado, nota-se que, apesar das reformas realizadas, aspectos indeléveis da estrutura institucional não foram alterados, o que, consequentemente, limita a aplicação prática do que é proposto.

PALAVRAS-CHAVE: América Latina. Democracia. Reformas políticas.

RESUMEN: Este artículo discute los programas reformistas en Bolivia, Brasil, Ecuador y Venezuela, a lo largo del siglo XXI, y sus limitaciones coyunturales. En ese contexto, las cuestiones económicas, jurídicas, políticas y sociales de nivel doméstico e internacional son analizadas como factores de contradicción que explican el mantenimiento del sistema capitalista y la dificultad de realización plena del régimen democrático en la región. Considerando las particularidades de cada Estado analizado, se nota que, pese las reformas realizadas, aspectos indelebles de la estructura institucional no fueron alterados, lo que, consecuentemente, limita la aplicación práctica de lo que es propuesto.

PALABRAS CLAVE: América Latina. Democracia. Reformas políticas.

ABSTRACT: This article discusses the reformist programs in Bolivia, Brazil, Ecuador and Venezuela, during $21^{\text {st }}$ century, and their conjunctural limitations. In this context, economic, judicial, political and social issues of domestic and international order are analysed as factors of contradiction that explain the maintenance of capitalist system and the difficult to fully fulfil the democratic regime in the region. Considering the particularities of each State under review, it is notable that, despite the reforms carried out, indelible aspects of the

\footnotetext{
${ }^{1}$ Programa de Pós-Graduação em Relações Internacionais San Tiago Dantas (UNESP/UNICAMP/PUC-SP), São Paulo - SP - Brasil. Mestranda em Relações Internacionais. ORCID <http://orcid.org/0000-0001-8233-7309>. Email: barbara.brazolin@gmail.com

${ }^{2}$ Programa de Pós-Graduação em Relações Internacionais San Tiago Dantas (UNESP/UNICAMP/PUC-SP), São Paulo - SP - Brasil. Mestre em Relações Internacionais. ORCID <http://orcid.org/0000-0002-9203-1247>. Email: andre@araujo.me
} 
institutional structure have not been altered, which, consequently, limits the practical application of what is proposed.

KEYWORDS: Latin America. Democracy. Political reforms.

\section{Introdução}

A América Latina passou por diversos processos históricos desde a sua colonização, criando um particular cenário em termos políticos, econômicos e sociais. Com o fim das ditaduras latino-americanas, o projeto democrático-liberal dos países centrais chegou ao continente, buscando-se modificar estruturas políticas, sociais e econômicas então vigentes, tendo ideais europeus e norte-americanos como referências.

Entretanto, apesar de uma evolução nas políticas da região, assim como dos direitos constitucionalmente garantidos às sociedades de cada nação sul-americana, existem diversos problemas no que se refere à internalização de um modelo de democracia que não foi pensado no contexto e no território latino-americano, no qual se aplicou. Dessa maneira, a democracia nesses Estados se apresenta como um projeto muito frágil, sendo negligenciada por diferentes instâncias governamentais e não-governamentais, o que contudo não é um fenômeno exclusivo da América Latina.

Além de sua fragilidade, conforme explicado neste artigo, o projeto democrático nunca se realizou por completo, já que vários grupos minoritários foram esquecidos dentro de seus territórios nacionais, como os grupos indígenas e afrodescendentes. É a partir do debate dos regimes democráticos existentes no continente, com a crescente força de expressão que as mídias e a tecnologia forneceram às minorias, que o projeto democrático retorna, mostrando as limitações da política vigente nos Estados latino-americanos.

A partir dos aspectos apontados, neste artigo serão discutidas as recentes mudanças políticas e constitucionais na América Latina, com destaque aos fenômenos da Bolívia, do Brasil, do Equador e da Venezuela, à luz das tensões sociais, políticas e econômicas produzidas a partir dos programas econômicos neoliberais incorporados por estes países. Sendo assim, passa-se por um recorte temporal no qual há disputas de projetos ilustradas pelas mudanças de governo, ações de movimentos sociais, políticas econômicas implementadas e, compondo esse quadro, as alterações nas constituições para facilitar a execução dessas propostas.

Primeiramente, a partir do debate conceitual de democracia, agência e Estado, trazendo contribuições de autores como Guillermo O'Donnell, Boaventura de Souza Santos e 
Roberto Gargarella, entre outros, buscou-se refletir sobre a democracia na região, enfatizando as limitações das mudanças que ocorreram nos países latino-americanos, assim como das ações dos governantes de cada Estado, envolvendo o poder de agência dos setores oposicionistas, questões de ordem econômica e a participação popular no controle das políticas públicas. Dessa maneira, o debate dos conceitos de autores que também buscaram refletir sobre a democracia no continente nos auxiliou na discussão sobre as mudanças constitucionais, políticas e estruturais dos países latino-americanos, debatendo as estruturas sob as quais as conjunturas políticas latino-americanas são operadas, incluindo as constituições e as relações entre Estado e mercado.

\section{Estado, Agência e Democracia}

A partir do século XXI, a relação do Estado com a sociedade tem incorporado questões democráticas, entretanto, na visão de O’Donnell (2011), as relações necessárias entre a sociedade, o Estado e a estrutura democrática são ignoradas ou simplesmente colocadas em segundo plano, fazendo com que na realidade não existam Estados democráticos em si, mas sim Estados que abarquem regimes democráticos. Nesse entendimento, o pressuposto principal é o ser humano como agente reconhecido e amparado legalmente de direitos em seu espaço, não somente político, mas também civil, cultural e social. Tal reconhecimento, adquirido ao longo de conquistas desse agente, vai se moldando de acordo com os processos históricos

Assumindo uma definição mais abrangente de democracia, apresentada por Dahl (1989), tem-se definidas primeiramente as liberdades necessárias para que haja democracia e consequentemente eleições democráticas. A partir desta definição, para que qualquer método político seja efetivo para sua população é necessário que haja liberdades básicas garantidas aos cidadãos de um Estado. Tais esforços conceituais culminam na definição de um regime democrático, com condições concomitantes e necessárias como eleições limpas e institucionalizadas. É equívoco, portanto, afirmar que existem Estados democráticos, sendo que na verdade existem inúmeros direitos não respeitados na relação do Estado com sua sociedade, considerando que haja, em realidade, apenas Estados que em seu interior abarquem um regime democrático (O’DONNELL, 2011). 
Em um regime democrático as eleições devem ser institucionalizadas, apresentando competitividade, liberdade, igualdade e serem decisivas e inclusivas, sendo que o vencedor de tal eleição não deve ser impedido de assumir seu cargo. Na América Latina, no entanto, o projeto democrático, ou parte dele, só teve seu início com o fim dos regimes ditatoriais no final do século XX, e até hoje apresenta dificuldades para garantir democraticamente os direitos de seus cidadãos.

Ainda que a democracia tenha incluído, ao longo do tempo, o direito de votar e ser eleito a todos os cidadãos de seu país, as expectativas têm um papel fundamental, já que o jogo político se dá somente através dos mecanismos institucionalizados pelos governos. A aposta institucionalizada para O'Donnell representa uma expectativa universalista, na qual:

\begin{abstract}
A atribuição de direitos, liberdades e obrigações é universalista: espera-se que cada um(a) reconheça que, com certas exceções detalhadas pelo próprio sistema legal, todos(as) gozam dos mesmos direitos políticos, liberdades e obrigações. Qual é a aposta? Que, em uma democracia, cada ego deve aceitar que cada cidadão(dã) pode participar com seu voto e eventualmente sendo eleito(a) no ato, eleições limpas, que determina quem os governará durante um período. Esta é uma aposta institucionalizada porque é imposta a cada ego independentemente de sua vontade: ego deve aceitar a aposta mesmo quando acredita que permitir a certos indivíduos votar ou ser eleito e um sério erro. Ego não tem outra opção a não ser correr o risco de que indivíduos que, segundo ele, são "equivocados" ou "perigosos" sejam eleitos como resultado de eleições limpas. (O'DONNELL, 2011, p. 33).
\end{abstract}

Sendo assim, a aposta é importante pois a democracia política contemporânea é o único regime que apresenta tal expectativa institucionalizada, com um direcionamento universalista e inclusivo, garantindo a cidadania política, na qual as pessoas têm direitos e obrigações garantidos por lei, e determinados pela aposta democrática. A partir dessa união pressupõe-se a existência de um Estado onde exista um regime democrático, uma aposta institucionalizada e a cidadania política garantida (O’DONNELL, 2011). Como pode ser visto pela realidade brasileira, apesar de serem garantidas eleições aparentemente democráticas, a aposta institucionalizada, de que tais indivíduos eleitos garantirão e protegerão os direitos dos cidadãos a serem representados, é rompida, resultando no crescente descrédito nos governos nacionais sul-americanos estudados.

No entanto, apesar de se ter um aprofundamento nas questões de agência, Estado, governo e cidadania, permanece uma preocupação que é latente a todas as pessoas que estudam o desenrolar das políticas latino-americanas e suas peculiaridades. Tal problema é: 
[...] o escasso poder que na América Latina tem os governos eleitos democraticamente e, em geral, os estados que contêm um regime democrático, para governar efetivamente sobre questões importantes e, mais, para avançar na democratização e no bem-estar de seus respectivos países. (O'DONNELL, 2011, p. 70).

A institucionalização das leis, da aposta democrática, assim como dos métodos eleitorais, nos direciona ao debate sobre o Estado de Direito. O Estado de Direito, ou Rule of Law, teve seu início com a Magna Carta Libertatum na Inglaterra no ano de 1215, sendo o precursor da evolução jurídica nos termos de cumprimento das leis pelas autoridades governamentais. O princípio inicial do Estado de Direito, advindo da Grécia Clássica, entendia que as instituições políticas deviam ser regidas por leis e não pelos homens, sendo que o governo deveria também estar sujeitos às regras anteriormente estabelecidas. Apesar de atualmente o Estado de Direito estar vinculado aos debates sobre democracia, O'Donnell (2011) afirma que a concepção inicial não era democrática, apresentando exemplos de regimes políticos autoritários que se guiavam pelo Estado de direito e, no entanto, suprimiam a cidadania política.

Com os avanços da democracia no século XX entende-se que o Estado de direito democrático deve apresentar outras estruturas anteriormente ignoradas, tendo como núcleo um sistema legal no qual todas as regras definidas deveriam estar acima de qualquer órgão ou funcionário governamental, sem a possibilidade de infringir ou desfazer-se de tais regras por vontade de alguém. Sendo assim, em seu livro Democracia, Agência e Estado, Guillermo O'Donnell (2011) defende que não há a consolidação da democracia como um todo que abrange todas as instâncias de um Estado, no qual existem processos de democratização. O'Donnell ao apresentar o conceito de "não Estado de Direito", exemplificou casos latinoamericanos, demonstrando que tal denominação democrática, apesar de ser utilizada no continente americano não é inteiramente contemplada.

Compreendendo que o Estado de Direito passa por modificações, adota-se características de tal conceito a partir da proposta de Raz (1977), onde:

1. As leis devem ser prospectivas, públicas e claras; 2. As leis devem ser relativamente estáveis; 3 . A confecção de leis específicas [...] deve orientarse por regras gerais públicas, estáveis e claras; 4. A independência do poder judiciário deve estar garantida; 5 . Deve observar - se os princípios da justiça natural (ou seja, audiências judiciais abertas e equitativas e ausência de vieses nos processos); 6. Os tribunais devem ter poderes de revisão [...] para assegurar conformidade com o estado de direito; 7. Os tribunais devem ser facilmente acessíveis; e 8. Não se deve permitir que o critério das 
instituições de prevenção de delito perverta a lei (RAZ, 1977 apud O'DONNELL, 2011, p. 117).

Com a delimitação das características do Estado de Direito, é entendido que todos devem estar submetidos à lei. Grande parte das transgressões às leis são realizadas pelos funcionários da burocracia estatal, a partir de seus cargos ou de suas relações com outros atores ou associações. As falhas na legalidade também se dão quando atores privados cometem atos ilícitos, facilitados pela transgressão iniciada por um funcionário estatal, o que representa as novas territorialidades existentes dentro de um Estado (O’DONNELL, 2011).

\begin{abstract}
Estas falhas da legalidade podem incluir que o estado não se estenda sobre o conjunto do território que, pelo contrário, tem regiões governadas por diversos tipos de legalidade informal ou simplesmente maliciosa; e/ou direitos civis ou sociais, que embora sejam concedidos a todos, na realidade são negados a muitos; e/ou o acesso negado, ou extremamente dificultoso para muitos, aos tribunais e a outras instituições estatais pertinentes; e/ ou legislação aplicada de maneira repressiva a alguns enquanto os privilegiados a ignoram ou violam com impunidade; e/ou instituições de accountability horizontal que não podem ou se recusam a cumprir com suas responsabilidades; e/ou que a própria lei e as decisões dos tribunais envolvem critérios discriminatórios ou de exclusão; etc. (O'DONNELL, 2011, p. 118).
\end{abstract}

\title{
Avanços e limites das agendas reformistas na América Latina: tensões internas e externas
}

De acordo com Roberto Gargarella (2013), após as transições à democracia nos países latino-americanos, as constituições foram modificadas para atender às resoluções das crises do período. Desse modo, para o autor, diante do autoritarismo das ditaduras que se encerravam, buscaram evitar a repetição das violações aos direitos humanos. Em seguida, com a crise econômica da década de 1980, criaram condições para o estabelecimento do desenho econômico neoliberal e inserção dos Estados periféricos à economia globalizada. Por fim, as mais recentes mudanças objetivam equacionar os resultados legados pela aplicação dessa estrutura econômica. Contudo, os diversos grupos sociais possuem interesses distintos em cada conjuntura, o que tende a produzir constituições mistas, com características correspondentes a diversos atores, e com contradições internas ao seu texto, assim como externas às políticas praticadas. 
Segundo o autor, um exemplo de constituição que é contraditória é a brasileira, porque incorporou ampla gama de direitos sociais em seu processo constituinte, no entanto, o restante da estrutura legislativa atendeu à implementação das políticas econômicas neoliberais (GARGARELLA, 2013). Sendo assim, por um lado, o governo atendia as demandas de movimentos sociais e partidos, mas não assegurava meios para que esses direitos fossem executados, isto é, o reconhecimento formal de direitos não foi transformado automaticamente em políticas públicas garantidoras dos mesmos, para reduzir as desigualdades. Por outro lado, o programa do neoliberalismo era aplicado com resultados opostos aos previstos na lista de direitos constitucionais. Entendemos que esse fenômeno se perpetua 30 anos após a Assembleia Constituinte.

Ademais, o Brasil foi um dos poucos países que antes mesmo do fim da ditadura militar instituiu, através da Lei ${ }^{\circ} 6.683$, a anistia política, que em seu Artigo $1^{\circ}$ decretou:

É concedida anistia a todos quantos, no período compreendido entre 02 de setembro de 1961 e 15 de agosto de 1979, cometeram crimes políticos ou conexo com estes, crimes eleitorais, aos que tiveram seus direitos políticos suspensos e aos servidores da Administração Direta e Indireta, de fundações vinculadas ao poder público, aos Servidores dos Poderes Legislativo e Judiciário, aos Militares e aos dirigentes e representantes sindicais, punidos com fundamento em Atos Institucionais e Complementares. (BRASIL, 1979).

Ou seja, o Estado brasileiro falhou em garantir os direitos de seus cidadãos, em aplicar a lei igualmente a todos sem diferenciá-los por seu posicionamento social e político dentro do Estado, e, mesmo com a instauração de um regime democrático, até os dias atuais tal lei não foi revogada, sendo que, diferente de outros países latino-americanos que instauraram Comissões da Verdade antes de se debater a instituição da anistia, o Brasil somente teve sua Comissão da Verdade criada no ano de 2012 para apurar os crimes que violaram os Direitos Humanos durante o período ditatorial no país (BRASIL, 2012).

De acordo com Gargarella (2013), essa realidade é explicada por uma tensão interna em relação à estrutura do poder. O argumento central de sua obra é que a "sala de máquinas" - uma seção da constituição que afeta todo o seu funcionamento - é inalterada e, portanto, sustenta a organização liberal-conservadora, favorável à manutenção do status quo e contrária à inclusão política e social das classes populares, desde o século XIX. Nesse sentido, se essa estrutura não é alterada, as reformas em outras seções da constituição possuem limitações, por poderem ser bloqueadas pelos grupos estabelecidos no poder. Logo, nota-se, ao longo de mais 
de um século, a estabilidade da elite da organização política que perpassa diferentes governos e constituições, constituindo um traço comum à América Latina.

Isso posto, o trabalho de Juan Peñafiel (2016) contribui para a análise ao aprofundar a discussão acerca dos conflitos entre os múltiplos projetos de sociedade e de organização da relação entre Estado e sociedade. Sua compreensão da situação latino-americana posiciona a região no contexto da globalização e a influência econômica transnacional sobre os governos nacionais, o que ocasionou na reestruturação da chamada matriz "mercado-cêntrica". Em outros termos, é uma articulação entre sociedade civil, Estado e mercado consolidada com as redemocratizações, que deu os meios para as transformações nas economias, com o avanço do neoliberalismo como doutrina aplicada pelos governos da América Latina, a partir da década de 1980. Essa matriz sociopolítica, na qual o mercado é o garantidor do desenvolvimento, choca-se com a "Estado-cêntrica", que age contra o mercado e é usualmente apoiada por movimentos sociais.

\section{Mudanças políticas e constitucionais}

Frente ao exposto, cabe ressaltar algumas considerações a respeito das mudanças nas e das constituições. As reformas não existem isoladamente, mas estão inseridas em um arcabouço jurídico pré-existente, assim como num contexto de relações de poder entre grupos sociais que podem ter diferentes graus de aceitação às propostas de alterações (GARGARELLA, 2013). Dessa maneira, em uma perspectiva acumulativa e linear da História, as reformas reagem a partir de uma estrutura já estabelecida e apresentam projetos para solucionar problemas da sociedade. Nesse sentido, cabe ressaltar que há uma miríade de atores - individuais e coletivos, estatais e não-estatais - que possuem interesses a serem manifestados no ordenamento legal da sociedade e que, dependendo de suas condições de poder, podem constituir-se pontos de resistência ou de impulso às reformas. Esta característica limita os conteúdos dos planos de alteração, devido à dificuldade em afetar o grupo vigente no comando da estrutura política e distribuir o poder decisório na inclusão de outros grupos sociais.

Isso posto, destaca-se que países como Argentina, Brasil, Chile e Uruguai não promulgaram novas constituições sob seus governos de centro-esquerda, mas sim buscaram construir a normatividade dentro da ordem jurídica dos parlamentos, sem modificar aspectos centrais das constituições vigentes e que contradizem com os projetos políticos propostos. Em 
contrapartida, de acordo com Peñafiel (2016), as democracias contra-hegemônicas - categoria na qual se inclui os processos em La Paz, em Quito e em Caracas - objetivaram romper com a lógica neoliberal, por meio da democratização econômica, política e social e da alteração da institucionalidade estatal, apoiadas no maior papel do Estado. Contudo, as alterações constitucionais $^{3}$ não eliminaram a tensão com as elites, o que ameaça a estabilidade e a continuidade dos governos, assim como os pressiona a atender demandas de grupos conservadores, por manutenção do status quo econômico e por restrição da participação popular. Isso acontece tanto pelo controle dos capitais e dos meios de produção, quanto pela presença na estrutura institucional do Estado, construída, moldada e ocupada desde as independências por uma restrita parcela da população, que se alterna no governo. Desse modo, conforme Gargarella (2013) afirma, as reformas constitucionais, ainda que amplas, podem ser insuficientes se não alterarem a "sala de máquinas", ou seja, quem legalmente detém os recursos de poder do Estado para implementar o programa de reformas.

Então, apesar da retórica de ruptura e das propostas de refundação do Estado, os três países andinos apontados sofreram maior conflito e resistência às fórmulas econômicas neoliberais, mas não se dissociaram totalmente do modelo capitalista. Assim, as mudanças realizadas operaram dentro do sistema e buscaram reformá-lo, a partir da instalação dos chamados grupos progressistas nos aparatos governamentais. Cabe ressaltar que chegaram ao poder apoiados em amplas e heterogêneas coalizões políticas, com diversos setores sociais e seus respectivos interesses, o que se reflete nos textos constitucionais que foram escritos. Em síntese, o contexto histórico do período anterior pauta a centralidade do mercado como mediador das relações sociais e limita a atuação desses governos, que fazem mudanças sem rupturas estruturais. Paralelamente, os partidos eleitos com base em movimentos populares são demandados a atender questões sociais, de inclusão, de democratização e de reconhecimento de direitos. Portanto, o governo e, consequentemente, o Estado tornam-se um nó que recebe e responde às militâncias de movimentos sociais, mas também às elites políticas, econômicas, internacionais, partidos aliados e oposicionistas, entre outros grupos. Indubitavelmente, esse cenário ocasiona tensões e confrontos, além da limitação em projetar as reformas dos programas eleitos.

3 Na Venezuela, a Constituição entrou em vigor em 1999, no primeiro ano de mandato do presidente Hugo Chávez (Movimiento V República). No Equador, o processo constituinte publicou a carta magna em 2008, durante a presidência de Rafael Correa (Alianza País), iniciada em 2007. Na Bolívia, a nova Constituição foi promulgada em 2009, no governo de Evo Morales (Movimiento al Socialismo), no cargo desde 2006. O único caso de alteração profunda dessas 3 constituições está em curso atualmente, com a convocação de uma Assembleia Constituinte por Nicolás Maduro (Partido Socialista Unido de Venezuela), na Venezuela. 


\section{Limitações das reformas}

A conjuntura descrita acima é uma das causas que explicam as restrições aos projetos de mudanças apresentados pelos governos de esquerda e centro-esquerda na América Latina. Somam-se questões internacionais e condições indeléveis do modelo capitalista para compreender fatos como a rejeição da reeleição de Evo Morales, na Bolívia, a crise na Venezuela, a alteração programática do equatoriano Lenín Moreno, a derrota eleitoral do Frente para la Victoria, na Argentina, e a destituição de Dilma Rousseff, no Brasil. Entre as variáveis explicativas, vale citar a organização de partidos de direita para assumir o poder, a participação dos militares na política, a reorientação da política externa estadunidense para a região, o esgotamento da relação entre o padrão distributivo e a propriedade dos meios de produção, os preços do mercado internacional de commodities, o avanço das agendas das instituições financeiras multilaterais e os conflitos sociais entre as classes proprietárias e as trabalhadoras, entre outras variáveis.

O fator econômico é relevante para compreender o alcance das reformas propostas nos últimos anos. De acordo com Peñafiel (2016), o caso da Bolívia é representativo, porque houve inclusão de setores sociais que não eram reconhecidos antes - notadamente, os indígenas - e políticas de redistribuição de renda. Entretanto, manteve o modelo de extrativismo de recursos naturais, isto é, não modificou o cerne do sistema econômico que é associado à desigualdade social e à influência de grupos privados sobre o aparato estatal, apesar de uma parte do controle do aparato produtivo haver sido passado ao Estado. Dessa maneira, as reformas para conter (mas não eliminar) as medidas mais fortes do neoliberalismo, mas com a permanência do padrão econômico, geram tensões entre mercado, Estado e sociedade.

Não acreditando que haveria uma restauração imediata dos governantes de direita na América Latina, na perspectiva de Massimo Modonesi (2015), esse conjunto pode ser caracterizado como "revoluções passivas", que são "una serie de proyectos devenidos procesos de transformaciones estructurales pero limitadas, con un trasfondo conservador, impulsadas desde arriba y por medio de prácticas políticas desmovilizadoras y subalternizantes" (MODONESI, 2015, p. 23). Para o autor, a consolidação de tais governos, no início do século XXI, se sustentou na capacidade de construir hegemonia entre diferentes classes. Todavia, conforme argumentamos aqui, não houve o rompimento ou a substituição da lógica de poder, reproduzindo mecanismos avessos ao aprofundamento da democracia. 
Revisando a tradicional divisão tripartite das democracias representativas liberais, a Constituição venezuelana de 1999 é considerada um marco da democracia participativa, ao dividir a República em 5 poderes, Executivo, Legislativo, Judiciário, Cidadão e Eleitoral. Dessa forma, a população - ou, pelo menos, setores dela - decide não apenas através do voto em eleições, plebiscitos e referendos, mas também participa da gestão pública (SILVA; FABRIZ, 2013). Esse aspecto é criticado por Gargarella (2013), porque, em sua visão, a participação popular passa a ser uma atividade institucionalizada do Estado e controlada por seus mecanismos burocráticos. Na contemporaneidade, tal argumento encontra eco nos setores de oposição venezuelanos, que acusam a instrumentalização das massas, o aparelhamento do Estado e a dificuldade de separação entre governo, partido e movimentos sociais

Nesse contexto, em alguns países, a crise da institucionalidade democrática - na qual o sistema representativo não projeta a composição da sociedade - é acompanhada pelo fenômeno de desmobilização das bases populares de apoio, a partir da tendência conservadora em tais governos, com variações em cada país. Segundo Modonesi (2015), houve falta de interesse das administrações progressistas em empoderar a participação do povo, devido ao foco nas eleições e na tentativa de atenuar os conflitos sociais, atendendo interesses antagônicos, o que nos remete aos desenhos constitucionais contraditórios interna e externamente. Isso deve ser considerado à luz do fortalecimento do presidencialismo, como é apontado por Gargarella (2013). A centralidade e a verticalização da estrutura política mantiveram-se, apesar das reformas constitucionais, transições à democracia e eleições de novos governos. Para Peñafiel (2016), esse elemento dificulta a intermediação com os setores da sociedade e amplia as dificuldades do sistema democrático. Também Santos (2010) ressalta que o protagonismo do constitucionalismo transformador, na Bolívia e no Equador, foi paulatinamente transferido dos movimentos sociais para o Estado.

Essa alteração ocorre também com mudanças nas coalizões governistas, que se fragmentaram com partidos à direita e à esquerda no espectro político-ideológico, em um cenário de necessidade de maiorias parlamentares para aprovação das reformas constitucionais e/ou outras medidas legislativas. De acordo com Modonesi (2015), por um lado, na Bolívia e na Venezuela os blocos da situação se mantiveram mais coesos, apesar de tensões internas. Em Caracas, a centralização política foi reforçada através da fundação do Partido Socialista Unido de Venezuela (PSUV), que aglutinou os componentes favoráveis ao 
chavismo ${ }^{4}$. Por outro lado, um exemplo dessa mudança é o perfil dos governos do Partido dos Trabalhadores (PT), no Brasil. Notavelmente, a chapa eleita de Dilma Rousseff era formada também por Michel Temer (Movimento Democrático Brasileiro, MDB) que esteve envolvido com os partidos da oposição para a troca da presidência.

\section{O Estado de Bem-Estar Social e a Participação Social}

Como pontuado anteriormente a crise da institucionalidade democrática é refletida na não projeção da participação social no sistema político, onde não há representatividade, e muitas vezes nem mesmo o reconhecimento dos cidadãos para certas decisões políticas.

A partir do momento no qual o Estado não se estende por todo o território, pela heterogeneidade que ele abarca, é preciso ir além do debate até então proposto, incorporando aqueles que são deixados de lado pelas leis de um país, sem reconhecimento e sem garantias como cidadãos de seus direitos e deveres. Em seu texto La refundación del Estado en America Latina, Boaventura de Souza Santos (2010) apresenta a transição dos países latinoamericanos para a democracia entre os anos 1970-1980, no qual Estados já heterogêneos, apesar de aderirem ao projeto democrático junto às mudanças e pressões internacionais, ignoraram a pluralidade existente em seus territórios, aprofundando a desigualdade, se afastando cada vez mais do discurso do Estado de Direito..

Em sua visão Santos (2010) apresenta diferentes dimensões da transição dos povos ignorados a muito tempo, sejam eles camponeses, indígenas ou afrodescendentes, que tem seus movimentos reprimidos ao longo da história, ou, como entendido por Aníbal Quijano (2005), são negados com a criação do "outro", aquele que não é. Tais dimensões se baseiam no início e fim da transição, o tempo que é considerado e as totalidades onde ocorreu a transição, para todos aqueles que se encontram no "território excluído" da ação e respaldo estatal, a duração da transição é muito mais longa do que a transição democrática.

Para los pueblos indígenas la transición tiene la duración más larga: comienza con la resistencia a la conquista y al colonialismo y solo terminará cuando la autodeterminación de los pueblos sea plenamente reconocida. Para los movimientos afrodescendientes la transición comienza con la resistencia a la esclavitud y a la profundización del colonialismo y del capitalismo

${ }^{4}$ Em um processo ainda em curso, durante o governo de Nicolás Maduro, o governismo na Venezuela apresenta sinais de reestruturação em torno do Movimiento Somos Venezuela, liderado pela vice-presidenta Delcy Rodríguez. 
hecho posible por la esclavitud y solo terminará cuando acaben el colonialismo y la acumulación primitiva, que por ahora sostienen la permanencia del racismo y de formas de "trabajo análogo a la esclavitud". Finalmente, para los campesinos en sentido amplio (cholos, mestizos, pardos, ribeirinhos, caboclos, pescadores, indígenas o afrodescendientes), la transición comienza con las independencias y con la resistencia al saqueo de las tierras comunales, a la concentración de tierras en las manos de las oligarquías, ahora libres del control imperial, y al patrimonialismo y coronelismo, y solo terminará cuando la reforma agraria sea finalmente cumplida (SANTOS, 2010, p. 282)

Uma importante consideração em relação às minorias negligenciadas está no que se entende como espaço dentro do Estado, ou cosmovisões, sendo que as transições da ditadura para a democracia são colocadas em uma totalidade tomada como homogênea, ao considerar o território sem suas divergências internas. Por outro lado, os indígenas e afrodescendentes tem marcos distintos, com universos culturais próprios "siempre con el riesgo de que las ideas más fundamentales, los mitos más sagrados, las emociones más vitales se pierdan en el tránsito entre universos lingüísticos, semánticos y culturales distintos” (SANTOS, 2010, p. 283).

Um Estado ao não considerar sua heterogeneidade, apesar da transição democrática e das mudanças necessárias para ser um Estado democrático de Direito, com as características de direitos iguais a todos, não o pode ser, pois não abarca todos em seu território, já que todos não são iguais, marcados por suas peculiaridades e diferentes processos históricos que os envolve (O’DONNELL, 2011). Um importante pensamento em relação a essa complementaridade trazida por Boaventura à visão de O'Donnell, é que o reconhecimento dos direitos aos indivíduos deveria ser plural, no qual se poderia assumir que "tenemos el derecho a ser iguales cuando la diferencia nos inferioriza; tenemos el derecho a ser diferentes cuando la igualdad nos des-caracteriza" (SANTOS, 2010, p. 283).

Ao explorar as desigualdades produzidas pelo Estado ao longo de diferentes processos históricos, Santos (2010) aponta questões do capital na lógica neoliberal que estava presente durante o fim das ditaduras nos países latino-americanos. É nesse mesmo período que o conceito de Estado de bem-estar social se insere. O chamado Welfare State (WS), ou Estado de Bem-Estar Social, é um fenômeno contemporâneo, inicialmente entendido como um modelo compensatório para os problemas estruturais do capitalismo, no qual o grande desenvolvimento capitalista industrial no século XX intensifica a urbanização das relações sociais, resultando nas políticas sociais, como consequências naturais de tal desenvolvimento. 
No entanto, no pós-guerra houve uma ruptura com o sistema, no qual foram desenvolvidas novas relações com a sociedade. Com novos fenômenos políticos e sociais, os governantes precisavam de uma dimensão compensatória e produtiva de poder e controle, no qual se utilizou do discurso do bem-estar social para atuar. Foi a partir desse momento que o Estado de Bem-Estar Social assumiu condições produtivas da estrutura capitalista.

Na visão de Merkel (2002), ao apresentar a Theory of Justice de Rawls entende-se que é necessário um conjunto de políticas para construir condições estatais que constituam uma sociedade mais equitativa. É a partir da análise da construção da justiça como conceito político que são propostas diferentes dimensões aos países latino-americanos no âmbito do Estado de Bem-Estar. Tais dimensões se posicionam em favor da prevenção da pobreza, melhora da educação e capacitação ao mercado e inclusão no mercado de trabalho, destacando a necessidade da proatividade e dinamicidade na formação do capital de trabalho.

A proposta de refundação dos Estados latino-americanos busca não somente incluir a nova territorialidade das populações pormenorizadas, mas também buscar ultrapassar os limites do capitalismo e do final do colonialismo. Ao legitimar tais movimentos, a refundação do Estado se depara com uma série de dificuldades, sendo que um dos principais pontos para a ampliação da democracia e do Estado de direito é a união das forças, onde a luta dos oprimidos não deve ser encabeçada somente por eles, mas sim deve ter como aliança os grupos e classes sociais majoritários. Esse caminho exige não somente um diálogo intercultural com respeito, mas também o reconhecimento do outro, historicamente suprimido (SANTOS, 2010). A refundação do Estado, portanto, não implica somente na mudança da estrutura política existente, mas também na mudança das relações sociais, culturais e econômicas de cada Estado, criando um espaço novo para que os grupos oprimidos tenham oportunidades e que seus direitos, diferenciados ou não, sejam garantidos.

\section{Considerações finais}

Diante do apresentado, sintetizamos os pontos pelos quais nossa reflexão foi conduzida. $\mathrm{O}$ avanço do neoliberalismo, a partir do final do século XX, legou mecanismos nas organizações jurídica e burocrática dos Estados latino-americanos que tiveram continuidade com os governos de esquerda e centro-esquerda na Bolívia, no Brasil, no Equador e na Venezuela. Logo, apesar dos programas de revisão às políticas econômicas anteriores, em geral detecta-se que houve permanência da execução de políticas favoráveis ao mercado, 
apesar de haver graus específicos em cada caso. Paralelamente, apresentaram reformas na agenda social, visando expandi-la e democratizá-la, com apoio de setores sociais que compunham a base popular dos governos. No entanto, houve limitações que impediram a alteração da estrutura de poder, gerando conflitos entre os grupos envolvidos.

O contexto de redemocratização na América Latina coincidiu com o da implementação do neoliberalismo na região. Portanto, as estruturas jurídicas e políticas eram demandas por interesses tanto sociais quanto econômicos, o que gerou contradições no interior das instituições e que seguem até a atualidade, dificultando o avanço das agendas reformistas. Indubitavelmente, os processos ocorridos nos últimos anos em La Paz, em Brasília, em Quito e em Caracas possuem especificidades que os diferenciam. Contudo, ressalvadas as devidas particularidades, é possível generalizar e encontrar um eixo comum entre as quatro situações, pois apresentaram uma retórica de ruptura com o modelo socio-político-econômico precedente e tiveram iniciativas nessa direção. Entretanto, não chegaram a romper com as estruturas conservadoras, políticas e econômicas, calcadas no sistema há longo tempo.

Pelos argumentos expostos acima, dentro do quadro institucional existente, avalia-se que as democracias não foram plenamente consolidadas. Assim, tanto o Estado de Direito quanto o Estado de Bem-Estar Social encontram obstáculos para se realizarem. Nesse sentido, a garantia de direitos iguais a toda a população, a aplicação isenta de Justiça e a responsividade dos políticos eleitos são algumas características que não ocorrem no regime vivenciado na América Latina, ainda que sejam elementos democráticos prescritos nas constituições.

\section{REFERÊNCIAS}

BANCO MUNDIAL. Dados do Banco Mundial. 2017. Disponível em:

<http://data.worldbank.org>. Acesso em 7 jul. 2017.

BOITO JR., Armando.; BERRINGER, Tatiana. Brasil: Classes sociais, Neodesenvolvimentismo e Política Externa nos governos Lula e Dilma. Revista de Sociologia e Política, v. 21, n. 47, set., 2013.

BRASIL. LEI No 6.683. 1979. Disponível em: <http://www.planalto.gov.br/ccivil_03/leis/L6683.htm>. Acesso em: 10 jul. 2017.

BRASIL. Comissão Nacional da Verdade. 2012. Disponível em<http://www.cnv.gov.br/institucional-acesso-informacao/a-cnv.html>. Acesso em: 10 jul. 2017.

DAHL, R. Democracy and Its Critics. New Haven: Yale University Press, 1989. 
GARGARELLA, Roberto. Latin American Constitutionalism: 1810-2010: The Engine Room of the Constitution. Oxford: Oxford University Press, 2013.

MERKEL, W. Social justice and the three worlds of welfare capitalism. European Journal of Sociology, vol. 43, n.1. April. 2002.

MODONESI, Massimo. Fin de la hegemonía progresista y giro regresivo en América Latina: Una contribución gramsciana al debate sobre el fin de ciclo. Viento Sur, n. 142, oct., 2015.

O'DONNELL, Guillermo. Democracia, agência e estado: teoria com intenção comparativa. São Paulo: Paz e Terra, 2011.316 p.

PEÑAFIEL, Juan Jorge Faundes. América Latina y conflicto social en el siglo XXI:

Escenarios y debates sobre el descuajeringamiento de la relación Estado, mercado y sociedad civil. Revista Chilena de Derecho y Ciencia Política, v. 7, n. 2, mayo/agosto, 2016.

QUIJANO Aníbal. Colonialidade do poder, eurocentrismo e América Latina. Buenos Aires: CLACSO, 2005.

RAZ, J. The Rule of Law and Its Virtue. The University of Chicago Law Review, vol. 64, n. 3, p. $765-807,1977$.

SANTOS, Boaventura de Sousa. Refundación del Estado en América Latina: perspectivas desde una epistemología del Sur. Lima: Plural editores, 2010. Disponível em:

$<$ http://www.boaventuradesousasantos.pt/media/La\%20Refundaci\%C3\%B3n\%20del\%20Esta do.pdf>. Acesso em: 05 jul. 2018.

SILVA, Heleno Florindo da; FABRIZ, Daury César. "O gigante acordou”: Uma análise da democracia à luz do novo Constitucionalismo latino-americano. Derecho y Cambio Social, 2013.

\section{Como referenciar este artigo}

ARAUJO, André Leite.; NEVES, Bárbara Carvalho. Democracia e as agendas reformistas na América Latina. Rev. Sem Aspas, Araraquara, v. 7, n. 1, p. 33-48, jan./jun., 2018. ISSN: 2358-4238. DOI: 10.29373/semaspas.unesp.v7.n1.jan/jun.2018.11661 